\title{
ANALISIS KEDALAMAN AKUIFER AIR TANAH DENGAN METODE GEOLISTRIKDI DISTRIK SENTANI KOTA KABUPATEN JAYAPURA
}

\author{
Bleskadit Chaterine Damayanti ${ }^{1)}{\text {; } \text { Virman }^{2)} \text {; Johnson Siallagan }}^{\text {3) }}$ \\ ${ }^{1}$ Lembaga Penjaminan Mutu Pendidikan; bleskaditchaterine@ymail.com \\ 2.Program Studi Magister Pendidikan IPA, UNCEN; virman_uncen@yahoo.com \\ ${ }^{3}$ Program Studi Magister Pendidikan IPA, UNCEN; siallagan1968@gmail.com
}

\begin{abstract}
Geophysical research on geoelectric method configuration schlumburger has been carried out in Sentani Kota area, Jayapura district to analyze the depth of groundwater aquifers. The data consisted of seven points measurement spread in Sentani Kota areas namely Kampung Harapan, Hawaii, Kampung Sereh, Kompleks 751, Pasar Lama, Doyo Baru, and Kampung Toware. The data obtained was done by processing data with IP2WIN software, and then made a subsurface profile likes log. Based on data processing, the results obtained showed that in Kampung Harapan the potential groundwater aquifer was found with a resistivity value of $18 \Omega \mathrm{m}$ at a depth of $>17.9 \mathrm{~m}$. In the Hawaiian area potential groundwater aquifers are found with resistivity values of $8.92 \Omega m$ at a depth of $64.7 \mathrm{~m}$. In the Kampung Sereh area potential groundwater aquifers were found with resistivity values of $14 \Omega \mathrm{m}$ at a depth of $24 \mathrm{~m}$. In the complex area of 751 a depressed groundwater aquifer is found in two layers with a third layer resistivity value of $106 \Omega \mathrm{m}$ at a depth of $13.3 \mathrm{~m}$ and a fifth layer $81.8 \Omega \mathrm{m}$ at a depth of $>28.6 \mathrm{~m}$. In the Pasar Lama area groundwater aquifers were found with resistivity values of $102 \Omega \mathrm{m}$ at depths $>17.4 \mathrm{~m}$. In the Doyo Baru area, a potential depressed groundwater aquifer was found with a resistivity value of $50.1 \Omega \mathrm{m}$ at a depth of $123 \mathrm{~m}$. And in the Kampung Toware a potential groundwater aquifer is found with a resistivity value of $11.5 \Omega \mathrm{m}$ at a depth of $>27.7 \mathrm{~m}$. From the results of the study, in the Sentani City area, groundwater aquifers were arranged by lithology of sandstone.
\end{abstract}

Keywords : geoelectric method; aquifer; ground air; Sentani

ABSTRAK
Telah dilakukan penelitian geofisika metode geolistrik konfigurasi schlumburger di daerah Sentani Kota, kabupaten Jayapura untuk menganalisis kedalaman akuifer air tanah. Pengambilan data terdiri dari tujuh titik pengukuran yang tersebar di daerah Sentani Kota yaitu kampung Harapan, Hawai, kampung Sereh, kompleks 751, Pasar Lama, Doyo Baru, dan kampung Toware. Data yang didapat dilakukan pengolahan data dengan software IP2WIN, kemudian dibuat profil bawah permukaan berupa log. Berdasarkan pengolahan data, hasil yang diperoleh menunjukkan bahwa di kampung Harapan ditemukan akuifer air tanah yang berpotensi dengan nilai resistivitas sebesar $18 \Omega \mathrm{m}$ pada kedalaman $>17,9 \mathrm{~m}$. Di daerah Hawai ditemukan akuifer air tanah yang berpotensi dengan nilai resistivitas sebesar 8,92 $\Omega \mathrm{m}$ pada kedalaman 64,7 m. Di daerah kampung Sereh ditemukan akuifer air tanah yang berpotensi dengan nilai resistivitas sebesar $14 \Omega \mathrm{m}$ pada kedalaman $24 \mathrm{~m}$. Di daerah kompleks 751 ditemukan akuifer air tanah tertekan yang terdapat pada dua lapisan dengan nilai resistivitas lapisan ketiga sebesar $106 \Omega \mathrm{m}$ pada kedalaman $13.3 \mathrm{~m}$ dan lapisan kelima $81.8 \Omega \mathrm{m}$ pada kedalaman >28,6 m. Di daerah Pasar Lama ditemukan akuifer air tanah yang dengan nilai resistivitas sebesar $102 \Omega \mathrm{m}$ pada kedalaman $>17.4 \mathrm{~m}$. Di daerah Doyo Baru ditemukan akuifer air tanah tertekan yang berpotensi dengan nilai resistivitas sebesar 50,1 $\Omega$ m pada kedalaman $123 \mathrm{~m}$. Dan di kampung Toware ditemukan akuifer air tanah yang berpotensi dengan nilai resistivitas sebesar $11,5 \Omega \mathrm{m}$ pada 
kedalaman $>27,7 \mathrm{~m}$. Dari hasil penelitian, di daerah Sentani Kota, akuifer air tanah disusun oleh litologi satuan batupasir.

Kata kunci : metode geolistrik; akuifer; air tanah; Sentani

\section{PENDAHULUAN}

Air adalah salah satu bahan baku utama setelah udara yang dibutuhkan oleh makhluk hidup sampai mikroorganisme lainnya yang hidup di muka bumi ini, sehingga air yang bersihlah yang sangat dibutuhkan. Sumber air di wilayah Sentani Kota terdiri dari air hujan, sungai, dan danau. Sungai-sungai kecil yang dapat dimanfaatkan sebagai sumber air di distrik Sentani Kota berasal dari gunung cycloop, antara lain : sungai Belo, sungai Warno, sungai Toladan, dan sungai-sungai kecil lainnya yang kemudian bermuara ke danau Sentani yang pada umumnya sangat tergantung pada fluktuasi air hujan.

Menurut data BPS Kabupaten Jayapura 2018, perkembangan jumlah penduduk di Kabupaten Jayapura khususnya di Distrik Sentani Kota setiap tahunnya mengalami peningkatan, mengakibatkan penggunaan lahan untuk pemukiman dan industri semakin meningkat sehingga dapat menyebabkan air banyak tersedot oleh kegiatan industri yang memerlukan sejumlah air dalam menunjang produksinya. Sehingga perlu adanya penelitian tentang akuifer air tanah untuk menunjang akan kebutuan air di distrik Sentani Kota. Salahsatu metode penyelidikan akuifer air tanah adalah metode geolistrik

Metode geolistrik digunakan untuk mempelajari keadaan bawah permukaan dengan cara mepelajari sifat aliran listrik di dalam medium/batuan dibawah permukaan bui (Santoso, 2002). Metode geolistrik dalam eksplorasi air tanah telah digunakan dalam beberapa penelitian, dintaranya Geni dan Yuyun (2013), Virman (2016), Ady dan Adrian (2017), , dan lainnya. Metode geolistrik ini dimaksud untuk memperoleh gambaran mengenai struktur lapisan di bawah permukaan dan dapat mendeteksi lapisan akuifer air tanah pada kedalaman tertentu. Tujuan dilakukannya penelitian ini adalah untuk mengetahui nilai tahanan jenis maupun potensi akuifer air tanah di distrik Sentani Kota.

Geolistrik merupakan salah satu metode geofisika untuk mengetahui perubahan tahanan jenis lapisan batuan di bawah permukaan tanah dengan mengalirkan arus listrik DC (Direct Current) yang mempunyai tegangan tinggi ke dalam tanah. Injeksi arus ini menggunakan dua buah elektroda arus A dan B yang ditancapkan kedalam tanah dengan jarak tertentu. Semakin panjang elektroda $\mathrm{AB}$ akan menyebabkan aliran arus listrik bisa menembus lapisan batuan lebih dalam. Dengan adanya aliran arus 
listrik tersebut maka akan menimbulkan tegangan listrik di dalam tanah. Tegangan listrik yang terjadi di permukaan tanah diukur menggunakan multimeter yang terhubung melalui dua buah elektroda tegangan $(\mathrm{MN})$ yang jaraknya lebih pendek dari pada jarak elektroda arus AB. Maka untuk menghitung besarnya hambatan dapat dihitung dengan rumus :

$$
R=\frac{V}{I}
$$

Keterangan:

R menyatakan Hambatan Listrik ( ohm), V menyatakanTegangan listrik (Volt) dan I menyatakan Arus Listrik ( Ampere )

Bila posisi jarak elektroda $\mathrm{AB}$ diubah menjadi lebih besar maka tegangan listrik yang terjadi pada elektroda $\mathrm{MN}$ ikut berubah sesuai dengan informasi jenis batuan yang ikut terinjeksi arus listrik pada kedalaman yang lebih besar. Sehingga dapat menggunakan rumus :

$$
\rho=K \frac{\Delta V}{I}
$$

\section{METODE PENELITIAN}

Penelitian dilakukan di Distrik Sentani Kota, Kabupaten Jayapura, Papua. Dengan menggunakan metode Geolistrik, target yang ingin di ketahui adalah air bawah permukaan (air tanah). Penelitian ini terdiri atas 7 (tujuh) titik pengukuran Geolistrik konfigurasi schlumburger yang tersebar di daerah Sentani Kota dan dapat mewakili pemetaan akuifer air tanah. Gambar 1 diagram alir penelitian:
Gambar 1 Diagram Alir Penelitian

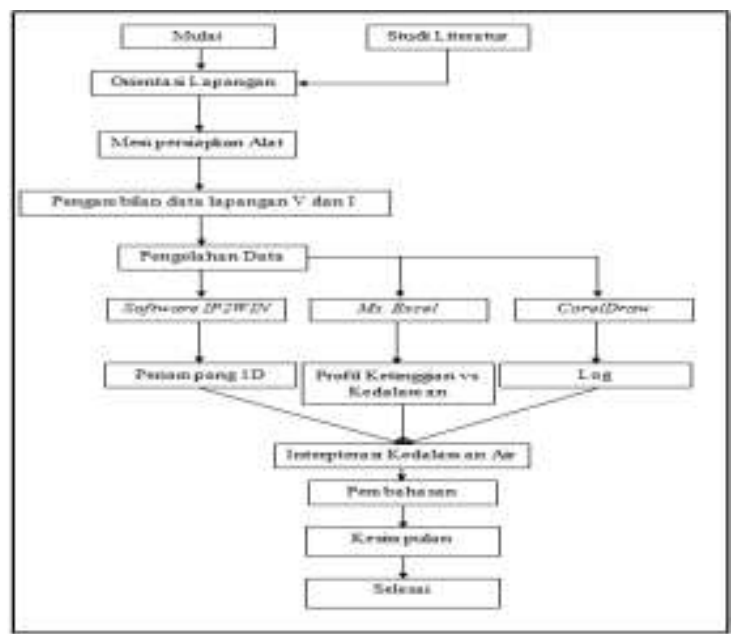

\section{HASIL DAN PEMBAHASAN}

Berdasarkan hasil yang diolah dengan oftware IP2WIN didapatkan nilai resistivitas batuan penyusun dan air tanah dengan menggunakan metode Geolistrik pada daerah kampung Harapan sebesar 18.1 ohm meter ,daerah Hawai sebesar 8.92 ohm meter, daerah kampung Sereh 14 ohm meter, daerah kompleks 751 sebesar 81.8 ohm meter, daerah Pasar Lama sebesar 102 ohm meter, daerah Doyo Baru sebesar 50.1 ohm meter, dan daerah kampung Toware sebesar $11.5 \mathrm{ohm}$ meter. Kedalaman air tanah dapat dilihat pada tabel 1:

Tabel 1 Profil Ketinggian vs Kedalaman

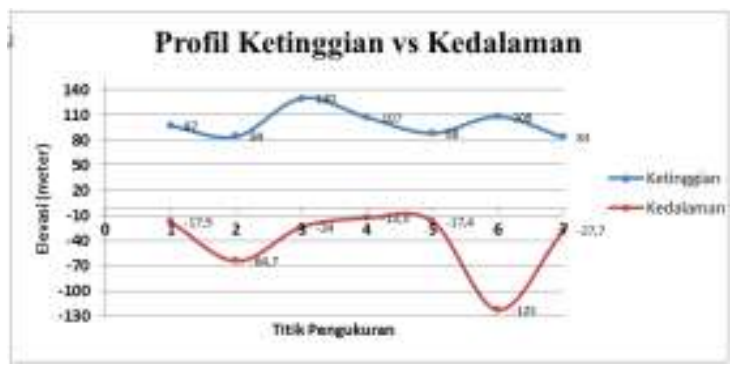

Berdasarkan tabel 1 kedalaman air tanah yang didapat yaitu di daerah 
kampung harapan >17.9 meter, daerah Hawai 64,7 meter, di daerah kampung sereh 24, di daerah kompleks 75113.3 meter, di daerah Pasar Lama $>17.4$, di daerah Doyo Baru 123 meter, di daerah kampung Toware >27.7 meter. Menurut Virman, Bagus E. B. Nurhandoko (2016) Pemetaan Lapisan Akuifer Formasi Makats Menggunakan Metode Geolistrik Tahanan Jenis

\section{SIMPULAN DAN SARAN SIMPULAN}

Akuifer air tanah pada daerah penelitian memiliki nilai resistivitas antara 8.92 ohm meter - 102 ohm meter dan kedalaman akuifer air tanah dengan menggunakan metode geolistrik di Distrik Sentani Kota berkisar antara 13.3 meter 123 meter.

\section{SARAN}

Saran yang perlu diberikan adalah perlu adanya data pendukung seperti data pengeboran, agar interpretasi data resistivitas yang dihasilkan sesuai dengan keadaan bawah permukaan.

\section{UCAPAN TERIMA KASIH}

Penulis mengucapkan terima kasih kepada Virman, atas bimbingan yang sangat bermanfaat serta dukungan semua pihak dari awal hingga selesainya proses penulisan ini.

\section{DAFTAR PUSTAKA}

Santoso, Djoko. 2002. Pengantar Teknik Geofisika. Bandung : ITB Press;

Virman, dan Bagus E. B. Nurhandoko. 2016. Pemetaan Lapisan Akuifer Formasi Makats Daerah Tanah Hitam Distrik Abepura Menggunakan Metode Geolistrik Tahanan Jenis. Wahan Fisika, 1 (2);

Geni, Dipatunggoro, Dan Yuyun Yuniardi. 2013. Penyelidikan Pendugaan Geolistrik untuk Penelitian Air Tanah di Asrama Rindam Sentani Kabupaten Jayapura Provinsi Papua. Bulletin of Scientific Contribution, Volume 11 ;

Ady Purnama, dan Adrian Noval. 2017. Kajian Potensi Air Tanah Dengan Pengujian Geolistrik Di Desa Telonang, Kabupaten Sumbawa Barat. Jurnal Saintek, Vol 2 (No.1). 